\title{
REVIEW
}

\section{Nodal staging of colorectal carcinomas and sentinel nodes}

\section{G Cserni}

J Clin Pathol 2003;56:327-335

This review surveys the staging systems used for the classification of colorectal carcinomas, including the TNM system, and focuses on the assessment of the nodal stage of the disease. It reviews the quantitative requirements for a regional metastatic work up, and some qualitative features of lymph nodes that may help in the selection of positive and negative lymph nodes. Identification of the sentinel lymph nodes (those lymph nodes that have direct drainage from the primary tumour site) is one such qualitative feature that is claimed to allow the upstaging of colorectal carcinomas via an oriented, enhanced pathological work up. Current evidence in favour of a change in the requisite of assessing as may lymph nodes as is possible, and concentrating the efforts on only a selected number of lymph nodes, is weak.

Correspondence to:

Dr G Cserni, Department of Pathology, Bács-Kiskun County Teaching Hospital, Nyiri ut 38, POB 149,

Kecskemét, Hungary: cserni@freemail.hu

Accepted for publication 20 December 2002
$M$ etastasis to regional lymph nodes (LNs) is one of the most important factors relating to the prognosis of colorectal carcinomas (CRCs), and the information on nodal involvement is an important part of all major CRC staging systems. Patients with metastatic LNs have a shorter survival and may require adjuvant systemic chemotherapy. It is thought that nodal involvement alone is not sensitive enough to discriminate between patients with a poor or a better prognosis, because up to $20-40 \%$ of patients with tumours infiltrating through the muscular wall, but without demonstrated nodal involvement, die of their cancer. A possible explanation and a partial cause of this phenomenon may be the failure to identify LN metastases when they are present. The aims of this review are to survey the different staging systems used for CRCs, to give an overview on quantitative recommendations for nodal staging, and to include some qualitative aspects of LNs that may promote the better identification of nodal involvement. Sentinel lymph node (SN) studies are also summarised within this last context, and as a means of selecting LNs for an enhanced pathological investigation.

\section{COLORECTAL CARCINOMA STAGING SYSTEMS}

Cuthbert Dukes, a pathologist at St Mark's Hospital, London, published his famous prognostic classification for rectal carcinomas 70 years ago. ${ }^{1}$ He used the letters A, B, and C to classify and stage the disease, basing his observations on the results of 215 rectal cancers that exhibited a worsening prognosis in parallel with a more advanced stage. Later, it was found that this system was also suitable for the staging of colon carcinomas. ${ }^{23}$ This classification was later modified slightly by Dukes and his colleagues: they divided group $\mathrm{C}$ into two subcategories, assigning stage $\mathrm{Cl}$ to those carcinomas with nodal metastases, but no metastasis in the apical nodes, and stage C2 to those tumours that displayed apical node involvement (table 1). With time, many other classifications and staging systems involving the use of the same letters were introduced (table 1). The original Dukes's classification and its modifications with the letters A, B, C, and sometimes even $\mathrm{D}$ assigned to different stages and prognostic groups of CRCs remain popular and are still widely used. It seems that “Dukes's C CRC" will long continue as the most common expression for node positive CRCs. The same seems true for "Dukes's B CRC", referring to node negative $\mathrm{T} 3$ tumours.

However, the fact that the classifications listed in table 1 involve the same letters, but with different meanings, and often appear with the eponymous form of the modified Dukes's classification has given rise to confusion and misuse. ${ }^{18}$ It is also somewhat surprising that even the name Dukes is often misspelled (many published works mention a Duke's classification).

\section{"Patients with metastatic lymph nodes have a shorter survival and may require adjuvant systemic chemotherapy"}

An alternative way to stage CRCs is the system based on the UICC TNM classification (table 2), which was last revised in 2002. From 2003, all tumours are expected to be staged on the basis of this most recent version. Although the A, B, C, and D based staging systems are said to be confusing, ${ }^{18}$ it is also believed that modifications and revisions of the TNM system may likewise give rise to some confusion. Whatever the staging system applied, a common language that pathologists, surgeons, and oncologists use and understand properly is a neccesity. The TNM system is a rather general system that is periodically updated in accord with new insight into the biology of

Abbreviations: CK-20, cytokeratin 20; CRC, colorectal carcinoma; $L N$, lymph node; RT-PCR, reverse transcription polymerase chain reaction; $S N$, sentinel lymph node; TME, total mesorectal excision 
Table 1 Staging classification of CRCs using letters $A$ to $C$ or $D$

\begin{tabular}{|c|c|c|c|c|}
\hline \multirow[b]{2}{*}{ 1st author or classification, year (ref) } & \multicolumn{2}{|l|}{ All without LN metastasis } & \multirow[b]{2}{*}{ Stage C } & \multirow[b]{2}{*}{ Stage D } \\
\hline & Stage A & Stage B & & \\
\hline Dukes, 1932 (1) & $\begin{array}{l}\text { Without penetration through the muscularis } \\
\text { propria; limited to the wall of the rectum }\end{array}$ & Penetrating through the bowel wall (muscularis propria) & With LN metastasis & No stage $D$ \\
\hline Gabriel-Dukes, 1935 (4) & $\begin{array}{l}\text { Without penetration through the muscularis } \\
\text { propria; limited to the wall of the rectum Same } \\
\text { as Dukes' }\end{array}$ & $\begin{array}{l}\text { Penetrating through the bowel wall (muscularis propria) } \\
\text { Same as Dukes' }\end{array}$ & $\begin{array}{l}\mathrm{C} 1 \text { : regional } \mathrm{LN} \text { involvement without apical } \\
\mathrm{LN} \text { involvement } \\
\mathrm{C} 2 \text { : apical } \mathrm{LN} \text { involvement }\end{array}$ & No stage $D$ \\
\hline $\begin{array}{l}\text { Kirklin, } 1949 \text { (5) "slight modification of the } \\
\text { Dukes's method" * }\end{array}$ & Limited to the mucosa & $\begin{array}{l}\text { B1: infiltrating the submucosa or the muscularis propria, } \\
\text { without penetrating this later } \\
\text { B2: penetrating through the muscularis propria }\end{array}$ & $\begin{array}{l}\text { With LN metastasis } \\
\text { Same as Dukes' }\end{array}$ & No stage $D$ \\
\hline Astler-Coller, 1954 (6) "modified Dukes's" * & $\begin{array}{l}\text { Limited to the mucosa } \\
\text { Same as Kirklin }\end{array}$ & $\begin{array}{l}\text { B1: infiltrating the submucosa or the muscularis propria, } \\
\text { without penetrating this later } \\
\text { B2: penetrating through the muscularis propria } \\
\text { Same as Kirklin }\end{array}$ & $\begin{array}{l}C 1 \text { : like } B 1 \text { but with } L N \text { involvement } \\
C 2 \text { : like } B 2 \text { but with } L N \text { involvement }\end{array}$ & No stage $D$ \\
\hline Turnbull, 1967 (7) & $\begin{array}{l}\text { Without penetration through the muscularis } \\
\text { propria; limited to the wall of the rectum Same } \\
\text { as Dukes's }\end{array}$ & $\begin{array}{l}\text { Penetrating through the bowel wall (muscularis propria) } \\
\text { Same as Dukes' }\end{array}$ & $\begin{array}{l}\text { C: tumour metastasis to regional mesenteric } \\
\text { LNs, but no distant metastasis }\end{array}$ & $\begin{array}{l}\text { D: distant metastasis, seeding of tumour, } \\
\text { irremovable tumour because of parietal } \\
\text { invasion, adjacent organ invasion. }\end{array}$ \\
\hline $\begin{array}{l}\text { Gunderson, } 1974(8) \text { "modified } \\
\text { Astler-Coller"* }\end{array}$ & $\begin{array}{l}\text { Limited to the mucosa } \\
\text { Same as Kirklin }\end{array}$ & $\begin{array}{l}\text { B1: infiltrating the submucosa or the muscularis propria, } \\
\text { without penetrating this later } \\
\text { B2: penetrating through the muscularis propria } \\
\text { B3: lesions adherent to or invading adjacent organs or } \\
\text { structures }\end{array}$ & $\begin{array}{l}\text { C1: like B1 but with } L N \text { involvement } \\
\text { C2: like B2 but with } L N \text { involvement } \\
\text { C3: like B3 but with } L N \text { involvement }\end{array}$ & No stage $D$ \\
\hline Pihl, 1980 (9) & $\begin{array}{l}\text { A1: intramucosal or invading into submucosa } \\
\text { but not beyond } \\
\text { A2: infiltrating the muscularis propria but not } \\
\text { penetrating through this layer }\end{array}$ & $\begin{array}{l}\text { Penetrating through the bowel wall (muscularis propria) } \\
\text { Same as Dukes' }\end{array}$ & $\begin{array}{l}\text { C1: regional } L N \text { involvement without apical } \\
\text { LN involvement } \\
C 2 \text { : apical } L N \text { involvement } \\
\text { Same as Gabriel-Dukes }\end{array}$ & $\begin{array}{l}\text { D1: Tumour invading adjacent organs (such as } \\
\text { prostate, bladder, uterus, small bowel) D2: } \\
\text { Tumour with distant metastases }\end{array}$ \\
\hline $\begin{array}{l}\text { Australian clinico-pathological staging } \\
\text { system, } 1983(10) \dagger\end{array}$ & $\begin{array}{l}\text { A: invading into bowel wall, but not beyond the } \\
\text { muscularis propria; without } L N \text { or distant } \\
\text { metastasis }\end{array}$ & $\begin{array}{l}\text { B: spread beyond the muscularis propria into adjacent } \\
\text { tissue in continuity or into adjacent organs; without } L N \text { or } \\
\text { distant metastasis }\end{array}$ & $\begin{array}{l}\text { C: spread into or through muscularis } \\
\text { propria with } L N \text { metastases and without } \\
\text { distant metastases }\end{array}$ & $\begin{array}{l}\text { D: Evidence of cancer remaining locally or at } \\
\text { distant site }\end{array}$ \\
\hline $\begin{array}{l}\text { Gastrointestinal tumor study group, } 1985 \\
\text { (11) "modified Dukes's"* }\end{array}$ & A: not defined, probably same as Dukes' & $\begin{array}{l}\text { B1: not defined } \\
\text { B2: extension through the rectal wall }\end{array}$ & $\begin{array}{l}\mathrm{C} 1 \text { : metastasis in } 1 \text { to } 4 \mathrm{LNs} \\
\mathrm{C} 2 \text { : metastasis to more than } 4 \mathrm{LNs}\end{array}$ & No stage $D$ \\
\hline $\begin{array}{l}\text { Australian clinico-pathological staging } \\
\text { system, } 1987 \text { (12) modified }\end{array}$ & $\begin{array}{l}\text { A1: intramucosal } \\
\text { A2: invading into submucosa but not beyond } \\
\text { A3: infiltrating the muscularis propria but not } \\
\text { penetrating through this layer }\end{array}$ & $\begin{array}{l}\text { B1: beyond muscularis propria, free mesothelial surface } \\
\text { not invaded, no tumour in lines of resection, no distant } \\
\text { metastasis } \\
\text { B2: as for B1, but free mesothelial surface invaded (not } \\
\text { applicable to distal rectum) }\end{array}$ & $\begin{array}{l}\mathrm{C} 1 \text { : metastasis to local LNs, no tumour in } \\
\text { lines of resection, no distant metastasis } \\
\mathrm{C} 2 \text { : metastasis to an apical LN, no tumour } \\
\text { in lines of resection, no distant metastasis. }\end{array}$ & $\begin{array}{l}\text { D1: Tumour involving line of resection } \\
\text { D2: Distant metastasis present }\end{array}$ \\
\hline $\begin{array}{l}\text { Cohen, } 1989 \text { (13) "modified } \\
\text { Astler-Coller" * }\end{array}$ & With invasion into submucosa & $\begin{array}{l}\text { B1: with invasion into muscularis propria } \\
\text { B2: not well defined enough, corresponding to T3 or } \\
\text { T4NOMO of the TNM } \\
\text { B3: corresponding to T4NOMO of the TNM }\end{array}$ & $\begin{array}{l}\text { C1: like B1 but with } L N \text { involvement } \\
\text { C2: like B2 but with } L N \text { involvement } \\
\text { C3: like B3 but with } L N \text { involvement }\end{array}$ & No stage $D$ \\
\hline Hyder, 1990 (15) & $\begin{array}{l}\text { Without penetration through the muscularis } \\
\text { propria; limited to the wall of the rectum Same } \\
\text { as Dukes' }\end{array}$ & $\begin{array}{l}\text { Penetrating through the bowel wall (muscularis propria) } \\
\text { Same as Dukes' }\end{array}$ & $\begin{array}{l}\mathrm{C} 1 \text { : infiltration not beyond the muscularis } \\
\text { propria and } 1 \text { to } 4 \text { positive } L N s \\
C 2:>4 \mathrm{LNs} \text { positive, or any } \mathrm{LN} \text { metastasis } \\
\text { and penetration beyond muscularis propria }\end{array}$ & $\begin{array}{l}\text { D: widespread or contiguous organ spread, or } \\
\text { distant metastasis present }\end{array}$ \\
\hline AJCC, 2002 (16) "modified Astler-Coller" * & With invasion to submucosa & $\begin{array}{l}\text { B1: with invasion into but not through muscularis propria } \\
\text { B2: with invasion through muscularis propria } \\
\text { B3: corresponding to T4NOMO of the TNM } 6 \text { th edition }\end{array}$ & $\begin{array}{l}\text { C1: like B1 but with } L N \text { involvement } \\
\text { C2: like B2 but with } L N \text { involvement } \\
\text { C3: like B3 but with } L N \text { involvement }\end{array}$ & D: with distant metastasis \\
\hline
\end{tabular}


Table 2 Summary of TNM/pTNM categories from the last 3 editions of the UICC pTNM system for colorectal carcinoma and the corresponding disease stages 1416171920

\begin{tabular}{|c|c|c|c|}
\hline $\begin{array}{l}\text { TNM/pTNM } \\
\text { categories }\end{array}$ & 4th edition ${ }^{14}$ & \multicolumn{2}{|c|}{ 5-6th editions (modifications) 16171920} \\
\hline $\mathrm{Tx} / \mathrm{pTx}$ & \multicolumn{3}{|l|}{ Primary tumour cannot be assessed } \\
\hline TO/pTO & No evidence of primary tumour & & \\
\hline Tis/pTis & Carcinoma in situ & \multicolumn{2}{|c|}{ Carcinoma in situ (intraepithelial or intramucosal, with invasion of lamina propria) } \\
\hline $\mathrm{Tl} / \mathrm{pT} 1$ & \multicolumn{3}{|l|}{ Tumour invades submucosa } \\
\hline T2/pT2 & \multicolumn{3}{|l|}{ Tumour invades muscularis propria } \\
\hline T3/pT3 & \multicolumn{3}{|c|}{ Tumour invades through muscularis propria into subserosa or into non-peritonealised pericolic or perirectal tissues } \\
\hline $\mathrm{T} 4 / \mathrm{pT} 4$ & \multicolumn{3}{|c|}{ Tumour directly invades other organs or structures and/or perforates visceral peritoneum* } \\
\hline $\mathrm{Nx} / \mathrm{pNx}$ & \multicolumn{3}{|l|}{ Regional LNs cannot be assessed } \\
\hline $\mathrm{NO} / \mathrm{pNO}$ & \multicolumn{3}{|l|}{ No regional $L N$ metastasis } \\
\hline $\mathrm{N} 1 / \mathrm{pN} 1$ & Metastasis to $1-3$ pericolic or perirectal LNs & \multicolumn{2}{|c|}{ Metastasis to $1-3$ regional $L N s$} \\
\hline $\mathrm{N} 2 / \mathrm{pN} 2$ & Metastasis to 4 or more pericolic or perirectal LNs & \multicolumn{2}{|c|}{ Metastasis to 4 or more regional LNs } \\
\hline $\mathrm{N} 3 / \mathrm{pN} 3$ & $\begin{array}{l}\text { Metastasis to LNs along the course of a named } \\
\text { vascular trunk }\end{array}$ & \multicolumn{2}{|c|}{ No N3/pN3 category } \\
\hline$M x / p M x$ & \multicolumn{3}{|l|}{ Distant metastasis cannot be assessed } \\
\hline $\mathrm{MO} / \mathrm{pMO}$ & \multicolumn{3}{|l|}{ No distant metastasis } \\
\hline $\mathrm{Ml} / \mathrm{pMl}$ & \multicolumn{3}{|l|}{ Distant metastasis } \\
\hline Disease stages & 4th edition ${ }^{14}$ & 5 th edition 1920 & 6th edition ${ }^{16} 17$ \\
\hline Stage 0 & Tis NO MO & Tis NO MO & Tis NO MO \\
\hline Stage I & T1-T2 NO MO & T1-T2 NO MO & T1-T2 NO MO \\
\hline \multirow[t]{2}{*}{ Stage II } & \multirow[t]{2}{*}{ T3-T4 NO MO } & \multirow[t]{2}{*}{ T3-T4 NO MO } & Stage IIA: T3 NO MO \\
\hline & & & Stage IIB: T4 NO MO \\
\hline \multirow[t]{3}{*}{ Stage III } & \multirow[t]{3}{*}{ Any T N1-N3 MO } & \multirow[t]{3}{*}{ Any T N1-N2 MO } & Stage IIIA: T1-T2 N1 MO \\
\hline & & & Stage IIIB: T3-T4 NI MO \\
\hline & & & Stage IIIC: any T N2 MO \\
\hline Stage IV & Any T any N MI & Any T any N Ml & Any $\mathrm{T}$ any $\mathrm{N} \mathrm{Ml}$ \\
\hline
\end{tabular}

*Adherence to other structures or organs must be proved by histology for a pT4 classification: a grossly adherent tumour with no microscopic evidence of adherence is $\mathrm{T} 4$, but $\mathrm{pT}$.

$\mathrm{LN}$, lymph node.

malignant disease. It allows the inclusion of several prognostic variables (for example, the $\mathrm{R}$ classification for residual disease, or the L classification for lymphatic invasion), and therefore seems the staging system most suitable for universal usage. As suggested by a recent editorial, ${ }^{21}$ it is our language for cancer care. Although the definitions for the TNM categories are unchanged in the sixth edition of the TNM classification, ${ }^{17}$ there has been a minor change in the definition of LNs. Both in the TNM system ${ }^{19}$ and in the UK minimum dataset for reporting CRCs, ${ }^{22}$ tumour nodules in the pericolic or perirectal fat with no evidence of residual LNs were recorded as LNs if they were greater than $3 \mathrm{~mm}$, whereas in the revised TNM classification ${ }^{17}$ they are classified as LNs only if their form and smooth contour is consistent with an LN origin; otherwise, they are classified as venous invasion (category $\mathrm{V}$ in the TNM system) based on likelihood. This revision is substantiated by a study demonstrating the intravascular, perivascular, or perineural origin of these tumour nodules, and the worse prognosis associated with them, independently of their size. ${ }^{23}$

It should be borne in mind that staging systems are merely a convenient way to attempt to report uniformly a set of recognised prognostic features on which further treatment may be based, and the results of different treatment modes may be compared. Many factors influence the assessment of these features, nodal status being one of the most important. ${ }^{24-26}$ It is of primary importance in decisions relating to the administration of adjuvant chemotherapy, and provides an objective confirmation of adequate regional LN dissection. ${ }^{27}$

\section{THE NUMBER OF LYMPH NODES ASSESSED}

The number of LNs assessed depends on the number of LNs present in the patient, on the number of LNs removed by the surgeon, and on the number of LNs identified by the pathologist. It is also dependent on what are identified microscopically as LNs (for example, subserosal tumour nodules or nodes with adipose changes).
LNs are usually located in the vicinity of vascular channels, and are not evenly distributed throughout the pericolic fat or mesorectal tissues along the large bowel. ${ }^{28}$ Some studies have suggested that there are fewer LNs around the rectum than around other segments of the colon, ${ }^{29}{ }^{30}$ but other studies have reported similar numbers of LNs for the rectum and other parts of the large bowel. ${ }^{31}{ }^{32}$ The transverse colon has also been claimed to have fewer LNs than other segments in some studies. ${ }^{30}{ }^{31}$ The number of LNs present in the mesocolic or perirectal fat varies from individual to individual and, under certain conditions, the number of LNs may increase even in a given individual. This increase may be related to the reactive enlargement of the LNs that are present but too small to be detected, but de novo genesis of LNs may also contribute. ${ }^{33}$ As evidence in favour of a reactive increase in the number of LNs identifiable by palpation, we have documented that the number of LNs in each centimetre of large bowel segment is greatest in close proximity to tumours. ${ }^{34}$ Anatomical and physiological factors may influence the number of LNs assessed, and probably play a major role in differences of LNs assessed in different patients undergoing the same type of surgery for the same stage of disease, but these factors cannot be influenced.

The extent of surgery has an obvious bearing on the number of LNs identifiable. It seems evident that the length of the resected bowel segment also influences the number of assessable LNs, because a longer segment has more associated LNs than a shorter one (for example, a sigmoid resection versus a left hemicolectomy). The more radical the colon resection, the more mesocolic fat is removed, and the more LNs present in the specimen. For rectal cancers, total mesorectal excision $(\mathrm{TME})^{35}$ specimens contain more LNs than anterior resection specimens performed before the era of TME. Some of these nodes are involved and are not expected to be removed by conventional resection. ${ }^{36}$ Surgical factors influencing LN numbers may vary from institution to institution or from surgeon to surgeon, but these variations are expected to be relatively slight if the procedure is standardised. 


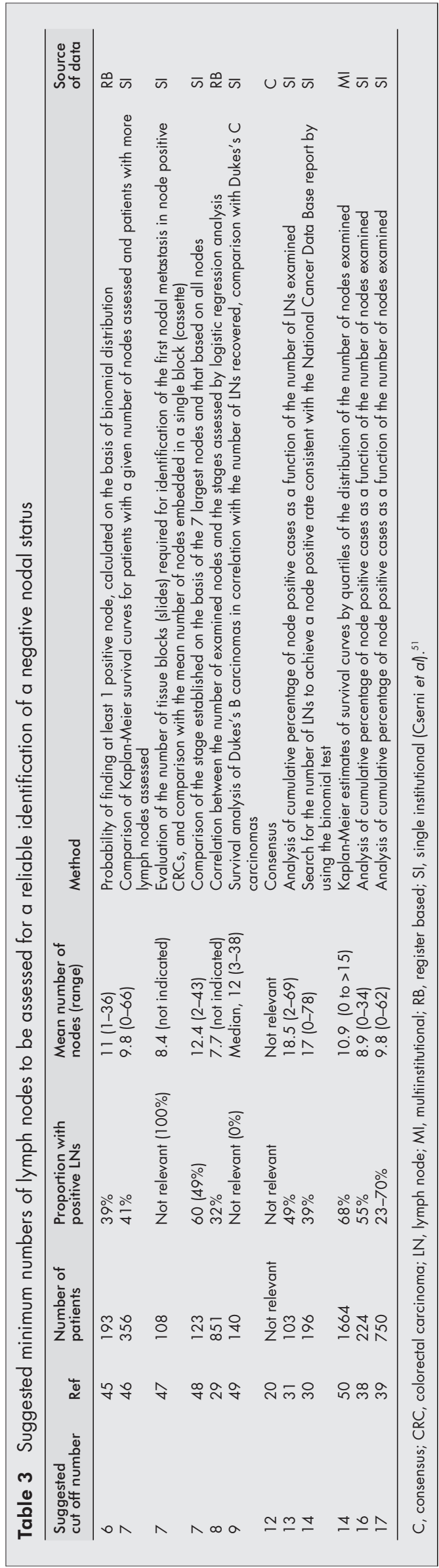

It seems that the pathological work up has a major role in the establishment of the nodal status from an adequate number of LNs; with no major changes in the surgical procedures, the number of LNs assessed could be increased by means of a more thorough dissection. ${ }^{37-39}$

"Overall, the quantitative requirement for the nodal staging of colorectal carcinomas is to recover as many lymph nodes as possible"

Guidelines on CRC reporting suggest that all LNs should be carefully dissected out and examined histologically, ${ }^{22}{ }^{40}$ but there is nevertheless a wide variation in the numbers of LNs assessed from study to study. It has been demonstrated that fat clearing or LN revealing substances can help in increasing the number of LNs recovered, ${ }^{15} 314142$ and that this can lead to the upstaging of some tumours reported as LN negative on the basis of palpation and manual dissection. A survival disadvantage has also been documented for these upstaged CRCs. ${ }^{43}$ However, the sensitivity of manual dissection varies widely between institutions: the mean of 6.2 LNs without fat clearance in a study indicating a disadvantage for patients with small metastatic LNs discovered only after fat clearance $^{31}$ appears inadequate, and a mean of 18.5 LNs after fat clearance is still below the mean reported in some studies where no special clearing agents were used. ${ }^{32}{ }^{37}$ Adequate fixation alone may also help in the retrieval of more $\mathrm{LNs}^{32}$ or in the identification of more LN positive CRCs. ${ }^{44}$

It seems logical that the more LNs a pathologist assesses, the more likely it is that a metastatic LN will be picked up. Assessment of only a few LNs is therefore associated with a smaller chance of finding metastatic ones. Likewise, in series of patients with CRC, the percentage of $\mathrm{LN}$ positive cases reported is lower if fewer LNs are assessed. ${ }^{29}{ }^{37}$ Accordingly, there have been suggested cut off points for a minimum number of LNs that should be assessed to achieve reliable nodal staging. The recommended mean number of LNs to be assessed also varies considerably, ranging from six to 17 (table 3). Such minimum values have been disputed. ${ }^{52}{ }^{53}$ It is generally understood that pathologists should try to recover as many LNs as possible, but that if they fail to identify the suggested numbers, the staging may still be accurate. ${ }^{5455}$

In some series it has been found that tumours that infiltrate less deeply, and therefore have a lower T category in the TNM system, are associated with fewer LNs recovered, probably as a consequence of smaller stimuli acting in favour of nodal hyperplasia or neogenesis. ${ }^{29}{ }^{41}$ It may also be hypothesised that metastatic CRCs have more LNs that attain a detectable size, which is why there are more LN positive cases in specimens with more LNs assessed; stated otherwise, the larger number of LNs assessed is not the reason why more LN positive CRC cases are found, but is rather a consequence of the development of nodal metastases and the more advanced stage. This is certainly true to some extent, and would militate against the painstaking work of recovering more and more LNs from CRC resection specimens, but two recent publications stress the quantitative recommendations of nodal assessment. Two independent studies, a large single institutional analysis of 2427 T3 CRCs including 1305 T3NO tumours, ${ }^{39}$ and a survival epidemiology and end results database analysis of 8574 T3NOMO CRCs, ${ }^{51}$ have documented a better survival rate for LN negative CRC cases with more LNs assessed, a fact that can be explained by the more accurate staging arising from the evaluation of more LNs. A further study has also documented an improved survival for LN negative patients with 18 LNs or more assessed, although this study correlated larger nodal numbers with better performed lymphadenectomy. ${ }^{56}$

Overall, the quantitative requirement for the nodal staging of CRCs is to recover as many LNs as possible. Because of the 
extra costs, routine use of fat clearing substances is not recommended, although this technique may well be of value. The advice on fat clearance or on the use of LN revealing solutions is usually restricted to cases where the number of LNs is considered suboptimum, although the optimum number cannot be adequately defined. The number of LNs assessed and the number containing metastases should be clearly stated in the reports.

\section{QUALITATIVE FEATURES OF LYMPH NODES THAT MAY INFLUENCE STAGING}

Adequate staging is dependent not only on how many LNs are assessed histologically, but also on which LNs are assessed. If an adequate selection between metastatic and non-metastatic LNs could be performed, the quantitative requirements summarised above might also be altered.

In general, metastatic LNs are larger than non-metastatic LNs. The size of positive and negative LNs from CRC resection specimens was found to be significantly different in two studies, but this difference was too small for the practical purpose of differentiating between the LN populations by palpation, and both studies found a significant overlap between the sizes of involved and uninvolved LNs. ${ }^{45}{ }^{57}$ Large LNs may be negative and small LNs may still harbour metastases. Several studies have prompted the view that "small LNs" (usually defined as $\leqslant 5 \mathrm{~mm}$ ) may be the only sites of metastases in CRC specimens. ${ }^{41-60}$ We found that most of the LNs recovered are $<5 \mathrm{~mm}^{48}{ }^{57}$ and therefore not above the limit assessable by imaging techniques (ultrasonography and computed tomography). This stresses the need for histopathology in the assessment of nodal status. It can be concluded that size alone is not a reliable discriminative feature between involved and uninvolved LNs. However, our series also suggested that the pathological study of the seven largest LNs could lead to the same staging as that of a mean of 12 LNs in $98 \%$ of cases. ${ }^{48}$

The distance from the tumour may also be a feature that could be of help in differentiating negative and positive LNs. Previously, we established that most metastatic LNs are located in the vicinity of the tumour involved bowel segment. When the bowel was divided perpendicularly to its longitudinal (luminal) axis, 99 of 100 CRCs could be adequately staged as LN positive or LN negative on the basis of LNs found in association with the tumour involved bowel segment and the $1 \mathrm{~cm}$ segments proximal and distal to the edges of the tumour. The nodal status of all 100 cases could be adequately defined in the pTNM system on the basis of the LNs beneath the tumour and the $3 \mathrm{~cm}$ segments proximal and distal to it. ${ }^{34}$ Incision of the mesocolic and pararectal fat helps in identifying more LN positive cases, probably by allowing better fixation and subsequently a better rate of identification of the subtumoral LNs, ${ }^{44}$ and this also favours the hypothesis that involved LNs are likely to be located in the vicinity of the tumour involved bowel segment. One of the first studies on lymphatic mapping in CRC, using patent blue dye, also revealed that most of the blue LNs identified were located within $3 \mathrm{~cm}$ of the tumour margin. ${ }^{61}$ However, other lymphatic mapping studies have afforded counter examples by demonstrating unexpected direct drainage from a tumour to an anatomically distant LN. ${ }^{62} 63$

\section{"Size alone is not a reliable discriminative feature between involved and uninvolved lymph nodes"}

The most promising qualitative feature of LNs that could help in a selection between them seems to be the occurrence of direct drainage from the tumour site. Despite previous findings on sentinal lymph nodes (SNs) in connection with parotid $^{64}$ and penile ${ }^{65}$ tumours, the SN concept was first well established in connection with cutaneous melanomas ${ }^{66}$ and breast carcinomas. ${ }^{67} 68$

\section{DIRECT DRAINAGE OF LYMPH FROM THE PRIMARY TUMOUR SITE: LESSONS LEARNT FROM OTHER CANCER SITES}

Surgeons are able to localise SNs in several types of tumour with vital dyes such as isosulfane blue or patent blue, with radiolabelled colloids and intraoperative $\gamma$ probes, or with a combination of these two methods. This has led to the formulation of the SN concept as a general rule for the lymphogenic spread of solid tumours, ${ }^{69}$ a concept that has not yet been well founded in neoplasms other than cutaneous malignancies and breast carcinoma. $^{70}$

From the two sites for which most experimental data have been achieved so far, we have learnt that SN biopsy is a very promising technique for the surgical and pathological staging of breast carcinomas, where it permits (1) the selective obviation of axillary dissection in $\mathrm{SN}$ negative and therefore presumably axillary LN negative patients, ${ }^{71}{ }^{72}(2)$ an oriented internal mammary node biopsy if the tumour drains to this region, ${ }^{73}$ and (3) a more detailed histopathological work up of a limited number of $\mathrm{LNs}^{74-76}$; it may also have a therapeutic role. $^{77}$ In cutaneous melanomas, SN biopsy allows the mapping of nodal regions, selective nodal dissection for SN positive patients, ${ }^{70} 78$ and the enhanced pathological assessment of a few selected LNs; the SN status is becoming a major prognostic factor. ${ }^{79}$ Draining patterns considered uncommon on an anatomical basis have been recorded for both tumour types: for example breast cancers have been reported to drain directly to level III axillary $\mathrm{LNs}^{80}{ }^{81}$ or even supraclavicular $\mathrm{LNs}^{82}{ }^{82}$ the last of which were previously regarded as distant metastases. ${ }^{19}{ }^{20}$ Melanomas, especially those of the trunk, may often drain outside the recognised lymphatic fields, including retroperitoneal LNs. ${ }^{83}$ Such experience also reflects the role that SN biopsy may play in the staging and treatment of CRCs.

\section{THE ROLE OF LYMPHATIC MAPPING IN COLORECTAL CARCINOMA}

Because the extent of surgery for CRCs is primarily defined by the location and size of the primary tumour, the identification of SNs did not initially influence the extent of surgery, ${ }^{84}$ but was considered a tool allowing a more detailed histological approach to those LNs that are the most likely sites of metastases. ${ }^{85}$ Missing these metastases was regarded as a possible cause of the treatment failures experienced in a rather high proportion of LN negative CRCs. ${ }^{85} 86$ Later, lymphatic mapping studies provided evidence that the purely anatomical concept of nodal spread was not true, and that SNs may be located at unexpected sites, as seen in breast carcinoma and melanoma. The anatomical concept of lymphogenic spread suggests that LNs around the bowel would be the first to be reached by metastases, followed by intermediate and apical LNs, and then more distant (for example, para-aortic) LNs. Metastases to proximal (apical) LNs - that is, LNs at the ligature of the main blood vessel supplying the resected large bowel segment involving a tumour-were incorporated in the first modification of the Dukes's staging system ${ }^{4}$ (table 1), and were also included in an earlier version of the TNM system (table 2). This was found to be of prognostic importance. ${ }^{12} 8788$ A failure of the anatomical order of spread is not exceptional and has long been known. The involvement of higher level LNs without metastases in LNs closer to the bowel is referred to as skip metastasis, the incidence of which may be as high as $10 \%{ }^{89}$ Lymphatic mapping studies have demonstrated that direct drainage may occur from a tumour site to apical or even paraaortic LNs, ${ }^{90}$ and this sheds new light on the definition of skip metastases. Even more surprisingly, the SNs may be located at sites relatively distant from the primary tumour. Surgeons from the John Wayne Cancer Institute have documented a case of CRC located in the ascendent colon that drained to an $\mathrm{SN}$ at the splenic flexure; this $\mathrm{LN}$ proved to be 
the only positive LN resected with the colon, but was outside the margins of a standard right hemicolectomy, the operation usually performed for a primary carcinoma at the given location. ${ }^{62}{ }^{63}$ Sterk et al reported on the detection of extramesorectal (iliac) LNs by rectal lymphoscintigraphy in four of 16 patients investigated, although they expressed doubts about the adequacy of their submucosal injections, and stated that deeper injections of the radiocolloid could be the cause for this high frequency. ${ }^{91}$ Larger series published to date suggested that unexpected lymphatic drainage occurs in $4-8 \%$ of cases ${ }^{86}{ }^{92}$ either as deep mesenteric SNs or as SNs "placed to the left" in cases of right sided colon tumours. The pinpointing of these LNs may lead to altered surgery if they are outside the margins of the standard resection. Therefore, lymphatic mapping and SN biopsy offer the promise of a more detailed pathological staging centred on a few LNs and a patient tailored planning of the extent of resection. Despite this promise, there are many confusing factors relating to the identification of the SNs in CRCs.

\section{TECHNICAL ISSUES OF SN BIOPSY IN COLORECTAL CANCER}

The technique of lymphatic mapping (as in the case of breast carcinoma) has many unstandardised variables, which include the nature of the tracer (type of dye, type of radiocolloid, use of a tracer alone or in combination), the method of administration (submucosal or subserosal), the nature of the procedure (in vivo mapping versus ex vivo mapping; open versus laparoscopic surgery), the definition of the SNs (any blue LNs or the first few blue LNs), etc. These technical differences may be responsible for discrepant results. Table 4 summarises the details of published lymphatic mapping series. Both the extremely large variation in the false negative rate and the relevant upper extreme of this parameter suggest that SN identification in CRCs is far from perfect. Alternately, the data could also suggest that the SN concept does not hold for CRCs, but there are a few larger series that militate against this last explanation.

\section{"Lymphatic mapping studies provided evidence that the purely anatomical concept of nodal spread was not true, and that sentinel lymph nodes may be located at unexpected sites, as seen in connection with breast carcinoma and melanoma"}

On the whole, table 4 indicates that the best results in terms of reliability (low false negative rates) were attained with dynamic studies (either in vivo injection of the tracer and immediate in vivo identification of the SNs or ex vivo injection of the tracer and ex vivo identification of the SNs), because greater time scales may leave too much time for dye overflow; However, even with this method false negative results can occur. Small particle radiocolloids may also label further echelon LNs. ${ }^{105}$ Overflow of the tracers can also partly explain the rather high discrepancy in the labelling of LNs despite a single combined tracer administration (81\% of radioactive LNs were blue, and $76 \%$ of blue LNs were radioactive). ${ }^{90}$ Tumour size (and the depth of invasion) is a further possible factor increasing the false negative rate in some series, ${ }^{3861} 106$ and massive nodal involvement may also play a part in it. ${ }^{86} 94107$

\section{DETAILED ANALYSIS OF LYMPH NODES}

It is not a new finding that a more detailed microscopic assessment of LNs (serial or step sectioning) or a more sensitive method of detection of microscopic involvement (immunohistochemistry) of LNs can reveal tumour cells undetected by standard haematoxylin and eosin examination. ${ }^{108-111}$

One of the main advantages of SN biopsy is the concentration of detailed histopathology or ancillary techniques on a few LNs. The evidence to date is scarce, but serial sectioning and immunohistochemistry have been reported to upstage CRCs in $7-33 \%$ of cases (table 4). None of the articles listed in table 4 distinguishes between isolated tumour cells, micrometastases, and larger metastases, ${ }^{17}$ and the importance of detecting very small metastatic foci by enhanced histopathology or ancillary techniques is at present unclear, with some studies suggesting a survival disadvantage, ${ }^{112-114}$ and others suggesting the opposite, ${ }^{109-111}{ }^{115-117}$ If the technique of SN biopsy can be improved so as to reach a reasonable false negative rate in the range of $0-10 \%$, then a more detailed work up of SNs could be advised outside research protocols, but the time has not yet come for this shift.

Immunohistochemistry can certainly (artificially) decrease the false negative rate of SNs to predict the LN status of CRCs, as shown by the study of Wong and colleagues ${ }^{98}$ (table 4 ). Most of the investigations listed in table 4 used enhanced histopathology only for the SNs, and the validation of the SN theory in CRCs with an enhanced histology of both SNs and non-SNs is based on only 25 cases. ${ }^{85}$ This study demonstrated an upstaging rate of $12 \%$ for SNs and of $1.2 \%$ for non-SNs, therefore suggesting that the SNs are really the most likely sites of metastases if the method used to identify them is adequate.

Because CRCs are generally positive for cytokeratin 20 (CK$20)$, this offers an ideal target for the reverse transcription polymerase chain reaction (RT-PCR) based study of regional nodal status. ${ }^{118}$ However, even this sensitive and specific method for both SNs and non-SNs failed to improve the false negative rate in one study, ${ }^{90}$ again questioning either the validity of the SN theory for CRCs or the adequacy of the method used to identify SNs (table 4; in vivo tracer administration and ex vivo search for SNs). It was recently demonstrated that CK-20 is downregulated in CRC tissue samples, and the background expression may also be substantial, so that care must be taken when this single marker is used. ${ }^{119}$ Another study, using multiple marker RT-PCR (with primers for $\beta$ chain human choriogonadotrophin, hepatocyte growth factor receptor, and universal melanoma associated antigen, all of which are frequently positive in CRCs), resulted in a high rate of upstaging of SN negative CRCs. The markers were found to be specific, and upstaging occurred more frequently with tumours that invaded deeper through the anatomical layers of the bowel. ${ }^{86}$

It is still not clear whether or not SN biopsy with a targeted intensive pathology assessment can lead to greater insight into the biological relevance of micrometastases and isolated tumour cells.

\section{CONCLUSIONS}

Despite many attempts to define a minimum number of LNs that should be evaluated histologically to provide an adequate nodal staging of CRCs, it is advisable to assess as many LNs as possible. Although there may be some qualitative features of LNs that can be of help in the selection between them and the picking up of those that are more likely to harbour metastases, neither the size of the LNs nor their distance from the primary tumour allows a reliable selection. Lymphatic mapping may be a good adjunct to the surgical and pathological staging of CRCs by demonstrating unexpected lymphatic drainage. This review of the literature and our personal experience suggests that radioguided or dynamic dye guided studies with immediate identification of the SNs are the optimal methods for this, and the procedure is more adequate in early stage CRCs. Currently, the identification of SNs in CRCs is made uncertain by many reports of unacceptably high false negative rates, despite some optimistic results in other studies; outside research protocols, therefore, a detailed histopathology of these LNs is not justified. 
Table 4 Summary of non-duplicate lymphatic mapping and SN biopsy studies in CRCs

\begin{tabular}{|c|c|c|c|c|c|c|}
\hline First author, year (ref) & $\begin{array}{l}\text { Number of } \\
\text { cases }\end{array}$ & $\begin{array}{l}\text { Identification } \\
\text { rates }\end{array}$ & False negative rates & $\begin{array}{l}\text { Upstaged by enhanced SN } \\
\text { pathology }\end{array}$ & Method used & $\begin{array}{l}\text { Comment (definition of SNs, range of SNs, pathology } \\
\text { details) }\end{array}$ \\
\hline Thörn, 2000 (93) & 10 & $10 / 10(100 \%)$ & $1 / ?(\geqslant 10 \%)$ & $\mathrm{NI}$ & $\begin{array}{l}\text { Subserosal dye and radiocolloid in vivo, in vivo search for } \\
\text { blue SNs and ex vivo search for radioactive SNs }\end{array}$ & $\begin{array}{l}\text { Any blue } L N \text { identified in vivo and high activity } L N \text { s defined } \\
\text { as SN (range, NII); pathology details NI }\end{array}$ \\
\hline Evangelista, 2002 (94) & 11 & $10 / 11(91 \%)$ & $1 / 3(33 \%)$ & NA & $\begin{array}{l}\text { Subserosal dye (submucosal for distal rectal cancers) in } \\
\text { vivo, in vivo search for LNs }\end{array}$ & $\begin{array}{l}\text { First to third blue } L N \text { defined as SN (range, } 0-3 \text { ); HE of all } \\
\text { LNs }\end{array}$ \\
\hline Tsoulias, 2002 (95) & 14 & $14 / 14(100 \%)$ & $1 / 3(33 \%)$ & $2 / 13(15 \%)$ & $\begin{array}{l}\text { Endoscopic submucosal dye in vivo, in vivo laparoscopic } \\
\text { search for } \mathrm{SNs}\end{array}$ & First blue $L N s$ defined as $S N s$ (range, 1-3); $S S$, IHC of $S N s$ \\
\hline Bendavid, 2002 (96) & 20 & $18 / 20(90 \%)$ & $0 / 12 ?(0 \%)$ & $5 / 11 ?(45 \%)$ & Subserosal dye in vivo, in vivo search for $S N_{s}$ & $\begin{array}{l}\text { Any blue } L N \text { defined as } S N \text { (range, } N I \text {; mean, 3.9); SS, } \\
\text { IHC of } S N \text { s }\end{array}$ \\
\hline Waters, 2000 (97) & 22 & $20 / 22(91 \%)$ & $\begin{array}{l}2 / 3(66 \%) \mathrm{HE} \\
0 / 6(0 \%) \mathrm{HC}\end{array}$ & $1 / 15(7 \%)$ & Subserosal dye in vivo, in vivo search for $\mathrm{SNs}_{\mathrm{s}}$ & $\begin{array}{l}\text { Any blue } L N \text { identified in vivo defined as } S N \text { (range, NII; } \\
\text { IHC of } \mathrm{HE} \text { negative } S N s\end{array}$ \\
\hline Cserni, 1999 (38) & 25 & $24 / 25(96 \%)$ & $5 / 13(38 \%) \mathrm{HE}$ & NA & Subserosal dye in vivo, ex vivo search for $\mathrm{SNs}$ & $\begin{array}{l}\text { Any blue LN (range, 0-12) defined as possible SN; HE } \\
\text { staining of all LNs }\end{array}$ \\
\hline Merrie, 2001 (90) & 26 & $23 / 26(88 \%)$ & $\begin{array}{l}3 / 7(43 \%) \text { HE } \\
5 / 11(45 \%) \text { RT-PCR }\end{array}$ & $2 / 16(13 \%)$ & $\begin{array}{l}\text { Subserosal dye and radiocolloid in vivo, ex vivo search for } \\
\text { SNs }\end{array}$ & $\begin{array}{l}\text { High radioactivity LNs or first blue LNs by tracing efferent } \\
\text { and afferent lymphatic vessels (range, } 0-8 \text { ); HE and CK-20 } \\
\text { RT-PCR of half LNs for all LNs }\end{array}$ \\
\hline Wong, 2001 (98) & 26 & $24 / 26(92 \%)$ & $\begin{array}{l}5 / 12(42 \%) \mathrm{HE} \\
1 / 16(6 \%) \mathrm{HC}\end{array}$ & $4 / 12(33 \%)$ & Submucosal dye ex vivo, then search for $\mathrm{SNs}$ & $\begin{array}{l}\text { Any blue } \mathrm{LN} \text { defined as } \mathrm{SN} \text { (range, } 0-6) ; \mathrm{IHC} \text { of negative } \\
\text { SNs }\end{array}$ \\
\hline Firtzgerald, 2002 (99) & 26 & $23 / 26(88 \%)$ & $2 / 7(29 \%) I H C$ & $2 / 20(10 \%)$ & $\begin{array}{l}\text { Subserosal dye (submucosal for rectal cancers) ex vivo, } \\
\text { search for blue LNs }\end{array}$ & $\begin{array}{l}\text { Any blue } L N \text { defined as } S N \text { (range, } N I I \text {; } 3 \text { level } \mathrm{HE} \text { and IHC } \\
\text { of SNs }\end{array}$ \\
\hline Esser, 2001 (100) & 31 & $18 / 31(58 \%)$ & $1 / 3(33 \%)$ & NA & $\begin{array}{l}\text { Subserosal dye in vivo (ex vivo for distal rectal cancers, ex } \\
\text { vivo search for SNs }\end{array}$ & Any blue $L N$ defined as $S N$ (range, NI); HE for all LNs \\
\hline Kitagawa, 2000 (101) & 33 & $28 / 33(85 \%)$ & $2 / 8(25 \%)$ & NA & $\begin{array}{l}\text { Endoscopic submucosal radiocolloid in vivo, in vivo search } \\
\text { for } S N_{s}\end{array}$ & $\begin{array}{l}\text { Radioactive } L N s \text { defined as } S N s \text { (range, } N \text {; mean, 3.7); HE } \\
\text { for all LNs }\end{array}$ \\
\hline Feig, 2001 (102) & 48 & $47 / 48(98 \%)$ & $\begin{array}{l}10 / 16(63 \%) \mathrm{HE} \\
5 / 20(20 \%) \mathrm{HC}\end{array}$ & $4 / 31(13 \%)$ & $\begin{array}{l}\text { Subserosal dye in vivo, in vivo and ex vivo search for blue } \\
\text { LNs }\end{array}$ & $\begin{array}{l}\text { Any blue } L N \text { defined as } S N \text { (range, } 0-7 \text { ); SS and IHC of } \\
S N \text { s }\end{array}$ \\
\hline Joosten, 1999 (61) & 50 & $35 / 50(70 \%)$ & $12 / 20(60 \%) \mathrm{HE}$ & $2 / 15(13 \%)$ & $\begin{array}{l}\text { Subserosal dye (submucosal for distal rectal cancers) in } \\
\text { vivo, ex vivo search for blue LNs }\end{array}$ & $\begin{array}{l}\text { Any blue LN defined as SN (range, 0-16); CK IHC of HE } \\
\text { negative blue LNs }\end{array}$ \\
\hline Paramo, 2002 (103) & 55 & $45 / 55(82 \%)$ & $1 / 15(7 \%)$ & $6 / 36(17 \%)$ & Subserosal dye in vivo, in vivo search for $S N_{s}$ & $\begin{array}{l}\text { First 1-4 blue LNs defined as SNs (range, } 0-1) ; S S, I H C \text { of } \\
\text { SNs }\end{array}$ \\
\hline Bilchik, 2002 (86) & 100 & $97 / 100(97 \%)$ & $5 / 26(19 \%) \mathrm{HE}$ & $\begin{array}{l}18 / 74(24 \%) 2 \text { levels HE and IHC } \\
12 / 26(46 \%) \text { RT-PCR of IHC } \\
\text { negative SNs }\end{array}$ & $\begin{array}{l}\text { Subserosal dye in vivo, in vivo search for } \mathrm{SNs} \text {, or salvage } \\
\text { subserosal or submucosal dye ex vivo, for failed procedures }\end{array}$ & $\begin{array}{l}\text { Any blue } L N \text { defined as } S N \text { (range, } N) \text { ); SS, IHC and/or } \\
\text { RT.PCR of SNs }\end{array}$ \\
\hline Saha, $2000(92,104)$ & 131 & $130 / 131(99 \%)$ & $4 / 51(8 \%)$ & $6 / 86(7 \%)$ & Subserosal dye in vivo, in vivo search for $S N_{s}$ & $\begin{array}{l}\text { First 1-4 blue staining } L N s \text { defined as } S N_{s} \text { (range, } 0-4 \text { ); } S S \\
\text { and IHC of HE negative } S N_{s}\end{array}$ \\
\hline
\end{tabular}


Take home messages

- There have been many attempts to define the minimum number of lymph nodes ( $L N s$ ) that should be evaluated histologically to provide an adequate nodal staging of colorectal cancers (CRCs), but the best advice is still to assess as many $\mathrm{LN}$ s as possible

- Neither the size of the LN nor its distance from the primary tumour allows a reliable selection

- Because sentinel lymph nodes (SNs) may occur in unexpected places, lymphatic mapping may be a good adjunct to the surgical and pathological staging of CRCs, and radioguided or dynamic dye guided studies with immediate identification of the SNs are the optimal methods

- Currently, in routine practice, concentrating the efforts on only a selected number of $\mathrm{SNs}$ is not recommended

\section{REFERENCES}

Dukes CE. The classification of cancer of the rectum. J Pathol Bacteriol 1932;35:323-32.

2 Grinell RS. The spread of carcinoma of the colon and rectum. Cancer 1950;3:641-52.

3 Wood DA, Robbins GF, Zippin C, et al. Staging of cancer of the colon and cancer of the rectum. Cancer 1979:43:961-8.

4 Gabriel WB, Dukes C, Bussey HJR. Lymphatic spread in cancer of the rectum. BrJ Surg 1935;23:395-413.

5 Kirklin JW, Dockerty MB, Waugh JM. The role of the retroperitoneal reflection in the prognosis of carcinoma of the rectum and sigmoid colon. Surg Gynecol Obstet 1949:88:326-31.

6 Astler VR, Coller FA. The prognostic significance of direct extension of carcinoma of the colon and rectum. Ann Surg 1954;139:846-51.

7 Turnbull RB Jr, Kyle K, Watson FR, et al. Cancer of the colon: the influences of the no-touch isolation technique on survival rates. Ann Surg 1967:166:420-7.

8 Gunderson LL, Sosin H. Areas of failure found at reoperation (second or symptomatic look) following "curative surgery" for adenocarcinoma of the rectum. Cancer 1974;34:1278-92.

9 Pihl E, Hughes ESR, McDermott FT, et al. Carcinoma of the rectum and rectosigmoid: cancer specific long-term survival. A series of 1061 cases treated by one surgeon. Cancer 1980;45:2902-7.

10 Davis NC, Newland RC. Terminology and classification of colorectal adenocarcinoma: the Australian clinico-pathological staging system. Aust N Z J Surg 1983;53:211-21.

11 Gastrointestinal Tumor Study Group. Prolongation of the disease-free survival in surgically treated rectal carcinoma. N Engl I Med 1985;312:1465-72

12 Newland RC, Chapuis PH, Smyth EJ. The prognostic value of substaging colorectal carcinoma. A prospective study of 1117 cases with standardized pathology. Cancer 1987;60:852-7.

13 Cohen AM, Shank B, Friedman MA. Colorectal cancer. In: DeVita VT, Hellman S, Rosenberg SA, eds. Cancer-principles and practice of oncology, 3rd ed. Philadelphia: JB Lippincott, 1989:895-964.

14 Hermanek P, Sobin LH, eds. UICC TNM classification of malignant tumours, 4th ed. New York: Springer Verlag, 1987.

15 Hyder JW, Talbott TM, Maycroft TC. A critical review of chemical lymph node clearance and staging of colon and rectal cancer at Ferguson Hospital, 1977 to 1982. Dis Colon Rectum 1990;33:923-5.

16 Greene FL, Page DL, Morrow M, et al, eds. AJCC cancer staging manual, 6th ed. New York: Springer, 2002.

17 Sobin LH, Wittekind Ch, eds. UICC TNM classification of malignant tumours, 6th ed. New York: John Wiley and Sons, 2002

18 Kyriakos $M$. The president's cancer, the Dukes classification, and confusion. Arch Pathol Lab Med 1985;109:1063-6.

19 Sobin LH, Wittekind Ch, eds. UICC TNM classification of malignant tumours, 5th ed. New York: John Wiley and Sons, 1997

20 Fleming ID, Cooper JS, Henson DE, et al, eds. AUCC cancer staging manual, 5th ed. Philadelphia/New York: Lippincott-Raven Publishers, 1997.

21 Greene FL, Sobin LH. The TNM system: our language for cancer care. J Surg Oncol 2002; 80: 119-20.

22 The Royal College of Pathologists Working Group on Cancer Services. Minimum data set for colorectal cancer histopathology reports. London: Royal College of Pathologists, 1998.

23 Goldstein NS, Turner JR. Pericolonic tumour deposits in patients with $\mathrm{T} 3 \mathrm{~N}+\mathrm{MO}$ colon adenocarcinomas: markers of reduced disease free survival and intra-abdominal metastases and their implications for TNM classification. Cancer 2000;88:2228-38.

24 Compton C, Fielding LP, Burgart L, et al. Prognostic factors in colorectal cancer. College of American Pathologists consensus statement 1999. Arch Pathol Lab Med 2000;124:979-94.

25 Steele G, Jr, Tepper J, Motwani BT, et al. Adenocarcinoma of the colon and rectum. In: Holland JF, Frei E III, Bast RC, et al, eds. Cancer medicine, 3rd ed. Philadelphia: Lea and Febiger, 1993:1493-522.

26 Gennari L, Doci R, Rossetti C. Prognostic factors in colorectal cancer. Hepatogastroenterology 2000;47:310-14.

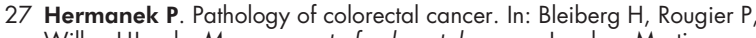
Wilke, HJ, eds. Management of colorectal cancer. London: Martin Dunitz, 1998:35-54.

28 Coller FA, Kay EB, Maclntyre RS. Regional lymphatic metastases of carcinoma of the colon. Ann Surg 1941:114:56-67.

29 Maurel J, Launoy G, Grosclaude P, et al. Lymph node harvest reporting in patients with carcinoma of the large bowel. A French population-based study. Cancer 1998;82:1482-6.

30 Wong JH, Severino R, Honnebier MB, et al. Number of nodes examined and staging accuracy in colorectal carcinoma. J Clin Oncol 1999;17:2896-900.

31 Scott KWM, Grace RH. Detection of lymph node metastases in colorectal carcinoma before and after fat clearance. Br J Surg 1989;76:1 165-7.

32 Crucitti $F$, Doglietto $G B$, Bellatone $R$, et al. Accurate specimen preparation and examination is mandatory to detect lymph nodes and avoid understaging in colorectal cancer. J Surg Oncol 1992;51:153-8.

33 Kaiserling E. Newly-formed lymph nodes in the submucosa in chronic inflammatory bowel disease. Lymphology 2001;34:22-9.

34 Cserni G, Tarján M, Bori R. Distance of lymph nodes from the tumour an important feature in colorectal cancer specimens. Arch Pathol Lab Med 2001;125:246-9.

35 Heald RJ, Ryall RDH. Recurrence and survival after total mesorectal excision for rectal cancer. Lancet 1986;i: 1479-82.

36 Reynolds JV, Joyce WP, Dolan J, et al. Pathological evidence in support of total mesorectal excision in the management of rectal cancer. $\mathrm{Br} J$ Surg 1996:83:1112-15.

37 Goldstein NS, Sanford W, Coffey M, et al. Lymph node recovery from colorectal resection specimens removed for adenocarcinoma. Trends over time and a recommendation for a minimum number of lymph nodes to be recovered. Am J Clin Pathol 1996;106:209-16.

38 Cserni G, Vajda K, Tarián M, et al. Nodal staging of colorectal carcinomas from quantitative and qualitative aspects. Can lymphatic mapping help staging? Pathol Oncol Res 1999;5:291-6.

39 Goldstein NS. Lymph node recoveries from 2427 pT3 colorectal resection specimens spanning 45 years. Recommendations for a minimum number of recovered lymph nodes based on predictive probabilities. Am J Surg Pathol 2002;26:179-89.

40 Jass JR, Morson BC. Reporting colorectal cancer. J Clin Pathol 1987:40:1016-23

41 Herrera-Ornelas L, Justiniano J, Castillo N, et al. Metastases in small nodes from colon cancer. Arch Surg 1987:122:1253-6.

42 Koren R, Siegal A, Klein B, et al. Lymph node-revealing solution: simple new method for detecting minute lymph nodes in colon carcinoma. Dis Colon Rectum 1997; 40:407-10

43 Scott KWM, Grace RH, Gibbons P. Five-year follow-up study of the fat clearance technique in colorectal carcinoma. Dis Colon Rect 1994; $37: 126-8$

44 Poller DN. Method of specimen fixation and pathological dissection of colorectal cancer influences retrieval of lymph nodes and tumour nodal stage. Eur J Surg Oncol 2000;26:758-62.

45 Hernanz F, Revuelta S, Redondo C, et al. Colorectal adenocarcinoma: quality of the assessment of lymph node metastases. Dis Colon Rectum 1994;37:373-6

46 Caplin S, Cerottini J-P, Bosman FT, et al. For patients with Dukes' B (TNM stage II) colorectal carcinoma, examination of six or fewer lymph nodes is related to poor prognosis. Cancer 1998:83:666-72.

47 Mainprize KS, Kulacoglu H, Hewavisinthe J, et al. How many lymph nodes to stage colorectal carcinomas? J Clin Pathol 1998;51:165-6.

48 Cserni G. The influence of nodal size on the staging of colorectal carcinomas. J Clin Pathol 2002:55:386-90.

49 Cianchi F, Palomba A, Boddi V, et al. Lymph node recovery from colorectal tumor specimens: recommendation for a minimum number of lymph nodes to be examined. World J Surg 2002;26:384-9.

50 Tepper JE, O'Connell J, Niedzwiecki D, et al. Impact of numbers of nodes retrieved on outcome in patients with rectal cancer. J Clin Oncol 2001:19:157-63.

51 Cserni G, Vinh-Hung V, Burzykowski T. Is there a minimum number of lymph nodes that should be histologically assessed for a reliable nodal staging of T3NOMO colorectal carcinomas? J Surg Oncol 2002:81:63-69.

52 Frankel K. Minimum number of lymph nodes to be recovered from colorectal resection specimens. Am J Clin Pathol 1997;107:494.

53 Bush ST. Minimum number of lymph nodes to be recovered from colorectal resection specimens. Am J Clin Pathol 1997;107:494.

54 Goldstein NS. Minimum number of lymph nodes to be recovered from colorectal resection specimens. Am J Clin Pathol 1997:107:494-5.

55 Sobin LH, Greene FL. TNM classification: clarification of number of regional lymph nodes for pNO. Cancer 2001;92:452.

56 Prandi $M$, Lionetto $R$, Bini $A$, et al. Prognostic evaluation of stage $B$ colon cancer patients is improved by an adequate lymphadenectomy: results of a secondary analysis of a large scale adjuvant trial. Ann Surg 2002;235:458-63.

57 Mönig SP, Baldus SE, Zirbes TK, et al. Lymph node size and metastatic infiltration in colon cancer. Ann Surg Oncol 1999;6:579-81.

58 Kotanagi H, Fukuoka T, Shibata Y, et al. The size of regional lymph nodes does not correlate with the presence or absence of metastasis in lymph nodes in rectal cancer. J Surg Oncol 1993;54:252-4.

59 Rodriguez-Bigas MA, Maamoun S, Weber TK, et al. Clinical significance of colorectal cancer: metastases in lymph nodes $<5 \mathrm{~mm}$ in size. Ann Surg Oncol 1996;3:124-30.

60 Bjelovic M, Kalezic V, Petrovic M, et al. Correlation of macroscopic and histological characteristics in the regional lymph nodes of patients with 

rectal and sigmoidal adenocarcinoma. Hepatogastroenterology
1998:45:433-8.

61 Joosten JJA, Strobbe LJA, Wauters CAP, et al. Intraoperative lymphatic mapping and the sentinel node concept in colorectal carcinoma. Br J Surg 1999;86:482-6.

62 Tsoulias GJ, Wood TF, Morton DL, et al. Lymphatic mapping and focused analysis of sentinel lymph nodes upstage gastrointestinal neoplasms. Arch Surg 2000;135:926-32.

63 Bilchik AJ, Saha S, Wiese D, et al. Molecular staging of early colon cancer on the basis of sentinel node analysis: a multicenter phase II trial. J Clin Oncol 2001;19:1128-36.

64 Gould EA, Winship T, Philbin PH, et al. Observations on a "sentinel node" in cancer of the parotid. Cancer 1960;13:77-8.

65 Cabanas RM. An approach for the treatment of penile carcinoma. Cancer 1977;39:456-66.

66 Morton DL, Wen DR, Wong J et al. Technical details of intraoperative lymphatic mapping for early stage melanoma. Arch Surg 1992; 127:392-9.

67 Krag DN, Weaver DL, Alex JC, et al. Surgical resection and radiolocalization of sentinel lymph node in breast cancer using a gamma probe. Surg Oncol 1993;2:335-40.

68 Giuliano AE, Kirgan DM, Guenther JM, et al. Lymphatic mapping and sentinel lymphadenectomy for breast cancer. Ann Surg 1994;220:391-8.

69 Bilchik AJ, Giuliano AE, Essner R et al. Universal application of intraoperative lymphatic mapping and sentinel lymphadenectomy in solid neoplasms. Cancer J Sci Am 1998;4:351-8.

70 Zervos EE, Burak WE, Jr. Lymphatic mapping in solid neoplasms: state of the art. Cancer Control 2002;9:189-202.

71 Cserni G. Axillary staging of breast cancer and the sentinel node. J Clin Pathol 2000;53:733-4 1 .

72 Borgstein PJ, Pijpers R, Comans EF, et al. Sentinel lymph node biopsy in breast cancer: guidelines and piffalls of lymphoscintigraphy and gamma probe detection. J Am Coll Surg 1998;186:275-3.

73 Cserni G, Pap Szekeres J. Internal mammary lymph nodes and sentinel node biopsy in breast cancer. Surg Oncol 2001;10:25-33.

74 Cserni G. Metastases in axillary sentinel lymph nodes in breast cancer as detected by intensive histopathological work up. J Clin Pathol 1999;52:922-4.

75 Van Diest PJ. Histopathologic workup of sentinel lymph nodes: how much is enough? J Clin Pathol 1999;52:871-3.

76 Cserni G. Complete step sectioning of axillary sentinel lymph nodes in patients with breast cancer. Analysis of two different step sectioning and immunohistochemistry protocols in 246 patients. J Clin Pathol 2002;55:926-31.

77 Cserni G. The potential therapeutic effect of sentinel lymphadenectomy. Eur J Surg Oncol 2002;28:689-691

78 Statius Muller MG, Borgstein P, Pijpers R, et al. Reliability of the sentinel node procedure in melanoma patients: analysis of failures after long-term follow-up. Ann Surg Oncol 2000;7:461-8.

79 Statius Muller MG, van Leeuwen PA, de Lange-De Klerk ES, et al. The sentinel lymph node status is an important factor for predicting clinical outcome in patients with stage I or II cutaneous melanoma. Cancer 2001:91:2401-8.

80 Kollias J, Gill PG, Chatterton BE, et al. Reliability of sentinel node status in predicting axillary lymph node involvement in breast cancer. Med J Aust 1999;171:461-5

81 Jansen L, Doting MHE, Rutgers EJTh, et al. Clinical relevance of sentinel lymph nodes outside the axilla in patients with breast cancer. Br J Surg 2000;87:920-5

82 McMasters KM, Wong SL, Tuttle TM, et al. Preoperative lymphoscintigraphy for breast cancer does not improve the ability to identify axillary sentinel lymph nodes. Ann Surg 2000;231:724-31.

83 Thompson JF, Uren RF, Shaw HM, et al. Location of sentinel lymph nodes in patients with cutaneous melanoma: new insights into lymphatic anatomy. J Am Coll Surg 1999;189:195-204.

84 Saha S, Wiese D, Badin J, et al. Technical details of sentinel lymph node mapping in colorectal cancer and its impact on staging. Ann Surg Oncol 2000;7:120-4.

85 Wiese DA, Saha S, Badin J, et al. Pathologic evaluation of sentinel lymph nodes in colorectal carcinoma. Arch Pathol Lab Med 2000; 124: 1759-63

86 Bilchik AJ, Nora D, Tollenaar RA, et al. Ultrastaging of early colon cancer using lymphatic mapping and molecular analysis. Eur J Cancer 2002;38:977-85.

87 Malassagne B, Valleur P, Serra J, et al. Relationship of apical lymph node involvement to survival in resected colon carcinoma. Dis Colon Rectum 1993;36:645-53.

88 Wright CM, Dent OF, Barker M, et al. Prognostic significance of extensive microsatellite instability in sporadic clinicopathologic stage $\mathrm{C}$ colorectal cancer. Br J Surg 2000;87: 1 197-202.

89 Yamamoto Y, Takahashi K, Yasuno M, et al. Clinicopathological characteristics of skipping lymph node metastases in patients with colorectal cancer. Jpn J Clin Oncol 1998;28:378-82.

90 Merrie AE, van Rij AM, Phillips LV, et al. Diagnostic use of the sentinel node in colon cancer. Dis Colon Rectum 2001;44:410-17.
91 Sterk $\mathbf{P}$, Keller L, Jochins $H$, et al. Lymphoscintigraphy in patients with primary rectal cancer: the role of total mesorectal excision for primary rectal cancer-a lymphoscintigraphic study. Int J Colorectal Dis 2002;17:137-42.

92 Saha S, Nora D, Wong JH, et al. Sentinel lymph node mapping in colorectal carcinoma: a review. Surg Clin North Am 2000;80: 181 1-19.

93 Thörn M. Lymphatic mapping and sentinel node biopsy: is the method applicable to patients with colorectal and gastric cancer? Eur J Surg 2000;166:755-8

94 Evangelista W, Sattoli MA, Malossi A, et al. Sentinel lymph node mapping in colorectal cancer: a feasibility study. Tumori 2002;88:37-40.

95 Tsoulias GJ, Wood TF, Spirt $M$, et al. A novel lymphatic mapping technique to improve localization and staging of early colon cancer during laparoscopic colectomy. Am Surg 2002;68:561-5.

96 Bendavid Y, Latulippe JF, Younan RJ, et al. Phase I study on sentinel lymph node mapping in colon cancer: a preliminary report. J Surg Oncol 2002;79:81-5.

97 Waters GS, Geisinger KR, Garske DD, et al. Sentinel lymph node mapping for carcinoma of the colon: a pilot study. Am Surg 2000;66:943-6.

98 Wong JH, Steineman S, Calderia C, et al. Ex vivo sentinel node mapping in carcinoma of the colon and rectum. Ann Surg $2001 ; 233: 515-21$

99 Fitzgerald TL, Khalifa MA, Al Zahrani $M$, et al. Ex vivo sentinel lymph node biopsy in colorectal cancer: a feasibility study. J Surg Oncol 2002;80:27-33

100 Esser S, Reilly WT, Riley LB, et al. The role of sentinel lymph node mapping in staging of colon and rectal cancer. Dis Colon Rectum 2001:44:850-6.

101 Kitagawa Y, Fujii $H$, Mukai $M$, et al. The role of the sentinel lymph node in gastrointestinal cancer. Surg Clin North Am 2000;80:1799-809.

102 Feig BW, Curley S, Lucci A, et al. A caution regarding lymphatic mapping in patients with colon cancer. Am J Surg 2001;182:707-12.

103 Paramo JC, Summerall J, Poppiti R, et al. Validation of sentinel node mapping in patients with colon cancer. Ann Surg Oncol 2002;9:550-4.

104 Wiese DA, Saha S. Evaluation of sentinel lymph nodes in colorectal carcinoma. Reply. Arch Pathol Lab Med 2001;125:999.

105 Kitagawa Y, Kitajima M. Gastrointestinal cancer and sentinel node navigation surgery. J Surg Oncol 2002;79:188-93.

106 Kitagawa Y, Ohgami M, Fujii H, et al. Laparoscopic detection of sentinel lymph nodes in gastrointestinal cancer: a novel and minimally invasive approach. Ann Surg Oncol 2001;8:86-9.

107 Kesthgar MRS, Amin A, I Taylor. Intraoperative lymphatic mapping and the sentinel node concept in colorectal carcinoma. Br J Surg 1999;86:1225-6.

108 van Wyk Q, Hosie KB, Balsitis M. Histopathological detection of lymph node metastases from colorectal carcinoma. J Clin Pathol 2000;53:685-7.

109 Jeffers MD, O'Dowd GM, Mulcahy $H$, et al. The prognostic significance of immunohistochemically detected lymph node micrometastases in colorectal carcinoma. J Pathol 1994;172:183-7.

110 Oberg A, Stenling R, Tavelin B, et al. Are lymph node micrometastases of any clinical significance in Dukes stages A and B colorectal cancer? Dis Colon Rectum 1998;41:1244-9.

111 Choi HJ, Choi YY, Hong SH. Incidence and prognostic implications of isolated tumor cells in lymph nodes from patients with Dukes B colorectal carcinoma. Dis Colon Rectum 2002;45:750-6.

112 Clarke G, Ryan E, O'Keane JC, et al. The detection of cytokeratins in lymph nodes of Dukes B colorectal cancer subjects predicts a poor outcome. Eur J Gastroenterol Hepatol 2000;1 2:549-52.

113 Liefers GJ, Cleton-Jansen AM, van de Velde CJH, et al. Micrometastasis and survival in stage II colorectal cancer. N Engl J Med 1998;339:223-8.

114 Rosenberg R, Hoos A, Mueller J, et al. Prognostic significance of cytokeratin-20 reverse transcriptase polymerase chain reaction in lymph nodes of node-negative colorectal cancer patients. J Clin Oncol 2002;20: 1049-55

115 Broll R, Schaver V, Schimmelpenning H, et al. Prognostic relevance of occult tumor cells in lymph nodes of colorectal carcinomas: an immunohistochemical study. Dis Colon Rectum 1997;40:1456-71.

116 Nakanishi Y, Ochiai A, Yamauchi Y, et al. Clinical implications of lymph node micrometastasis in patients with colorectal cancers. A case control study. Oncology 1999;57:276-80.

117 Noura S, Yamamoto H, Miyake Y, et al. Immunohistochemical assessment of localization and frequency of micrometastases in lymph nodes of colorectal cancer. Clin Cancer Res 2002;8:759-67.

118 Yun K, Merrie AEH, Gunn J, et al. Keratin 20 is a specific marker of submicroscopic lymph node metastases in colorectal cancer: validation by K-ras mutations. J Pathol 2000;191:21-6.

119 Vlems FA, Diepstra JHS, Cornelissen IMHA, et al. Limitations of cytokeratin 20 RT-PCR to detect disseminated tumour cells in blood and bone marrow of patients with colorectal cancer: expression in controls and downregulation in tumour tissue. Mol Pathol 2002;55: 156-63. 